\title{
PRODUÇÃO ESCRITA DE CONTOS NAS AULAS DE MATEMÁTICA, NA PERSPECTIVA DA RESOLUÇÃO DE PROBLEMAS
}

\author{
Márcia da Silva Santos Portela \\ Carloney Alves de Oliveira ${ }^{2}$
}

\begin{abstract}
RESUMO
Este estudo, fruto de uma dissertação vinculada ao Programa de Pós-Graduação em Ensino de Ciências e Matemática (PPGECIM/UFAL), propõe reflexões sobre a produção escrita de contos nas aulas de Matemática, na perspectiva da resolução de problemas, no cotidiano da sala de aula, buscando evidenciar os saberes matemáticos a partir da produção de contos. Trata-se de uma pesquisa qualitativa que adotou como método a pesquisa-ação e como campo empírico uma escola localizada no bairro do Brasil Novo, na cidade de Rio Largo/AL. Envolveu 35 alunos na faixa etária de 10 a 13 anos e usou como dispositivos de produção de dados observação participante, questionário aberto e produções textuais dos alunos. Os resultados revelaram indícios da potencialidade das atividades propostas na intervenção para a produção escrita dos contos, identificando saberes matemáticos tais como: medidas de tempo, geometria, localização e quantidades na perspectiva da resolução de problemas, aproximando os alunos da Matemática presente em sua realidade.
\end{abstract}

Palavras-chave: Leitura e produção de contos. Ensino da Matemática. Resolução de Problemas.

\section{WRITTEN PRODUCTION OF SHORT STORIES IN MATHEMATICS CLASSES FROM THE PROBLEM-SOLVING PERSPECTIVE}

\begin{abstract}
Part of a dissertation presented to the Graduate Program in Teaching of Sciences and Mathematics (PPGECIM / UFAL), this paper proposes reflections on the written production of short stories in mathematics classes from the problem-solving perspective, aiming to evince mathematical knowledge from these stories. Adopting an action research methodology, this qualitative research was conducted as a pedagogical intervention in a school located in Brasil Novo, a neighborhood in the city of Rio Largo / AL. Data on 35 students in the10-13 age bracket were gathered
\end{abstract}

\footnotetext{
1 Mestre em Ensino de Ciências e Matemática (PPGECIM/UFAL). Professora da Secretaria Municipal de Educação de Rio Largo e de Maceió, Alagoas, Brasil. Orcid iD: https://orcid.org/0000-0001-8576-8139. E-mail: pormar.al@gmail.com

2 Pós-Doutor em Educação (UFS). Doutor em Educação (UFAL). Professor da Universidade Federal de Alagoas, Maceió, Alagoas, Brasil. Orcid iD: https://orcid.org/0000-0002-2134-0587. E-mail: carloney.oliveira@cedu.ufal.br
} 
through participant observation, open questionnaire and textual production of students. Results revealed evidence of the potential of the activities proposed in the intervention for the written production of short stories, identifying mathematical knowledge, such as measurements of time, geometry, location and quantities in the problem-solving perspective, bringing students closer to the mathematics existing in their reality.

Keywords: Reading and production of stories. Mathematics teaching. Problem solving.

\section{PRODUCCIÓN ESCRITA DE CUENTOS EN CLASES DE MATEMÁTICAS DESDE LA PERSPECTIVA DE LA SOLUCIÓN DE PROBLEMAS}

\section{RESUMEN}

Este estudio, resultado de una disertación vinculada al Programa de Posgrado en Enseñanza de Ciencias y Matemáticas (PPGECIM / UFAL), propone reflexiones sobre la producción escrita de cuentos en las clases de Matemáticas desde la perspectiva de la resolución de problemas, en el aula, buscando resaltar el conocimiento matemático de la producción de cuentos, que es una investigación cualitativa que adoptó como método de investigación de acción y como campo empírico una escuela ubicada en el barrio de Brasil Novo, en la ciudad de Rio Largo / AL. Los estudiantes de 10 a 13 años de edad utilizaron la observación participante, el cuestionario abierto y la producción textual de estudiantes como dispositivos de producción de datos. Los resultados revelaron evidencia del potencial de las actividades propuestas en la intervención para la producción escrita de historias, identificando conocimiento matemático como tales como: mediciones de tiempo, geometría, ubicación y cantidades en la perspectiva de la resolución de problemas, acercando a los estudiantes a las Matemáticas El presente en tu realidad.

Palabras clave: Lectura y producción de cuentos. Enseñanza de las matemáticas. Solución de problemas.

\section{PARA COMEÇO DE REFLEXÃO...}

O gênero textual é a forma como a língua é empregada nos textos, em diversas situações de comunicação, de acordo com o seu uso (PADOVANI, 2005).

Entendemos que a comunicação possui algumas características básicas que fazem com que possamos identificar o gênero textual a qual cada texto pertence. Algumas dessas características são: o tipo de assunto abordado, quem está falando, para quem se está falando, qual a finalidade do texto, qual o tipo de texto (narrativo, argumentativo, instrucional, etc.) 
Tomando por base essas informações, selecionamos o gênero conto por este fazer parte do currículo desde a educação infantil, e pela diversidade que ele apresenta para a construção de um texto narrativo.

Acreditamos que, fazendo da produção de contos, nas aulas de Matemática delineadas com as orientações adequadas às propostas do desenvolvimento do que se pretende agregar a Língua Portuguesa e a Matemática, é possível compreender que o conto é um gênero conciso produzido em ambientes diversificados que cria um universo de seres e acontecimentos fictícios, e envolve as mais variadas temáticas e retrata a vida através da arte.

Nesse sentido, Bosi (1975, p.31) argumenta que o conto funciona como uma espécie de "poliedro capaz de refletir as situações mais diversas de nossa vida real ou imaginária"; e, por ser de pequena extensão, mais curto que a novela e o romance, é capaz de expressar de forma breve o conflito que o envolve.

Sobre a composição discursiva do gênero conto, em linhas gerais, Sarmento e Tufano (2004, p. 76), conceituam-na a partir dos seguintes elementos: "enredo, um único conflito e clímax, uma história com poucas personagens, tempo e espaço reduzidos e um desfecho". Salientamos que essa organização varia de conto para conto, não havendo uma sequência cronológica específica das ações na narrativa.

Dado o exposto, procuramos encontrar respostas para o problema: Quais são os saberes matemáticos evidenciados nas produções textuais, especificamente o gênero conto, nas aulas de Matemática, na perspectiva da resolução de problemas?

Para responder esta questão, realizamos um estudo com o objetivo geral de analisar os saberes matemáticos evidenciados nas produções textuais, nas aulas de Matemática, na perspectiva da resolução de problemas. Esse objetivo geral desdobrou-se nos seguintes objetivos específicos: identificar quais são as contribuições e potencialidades das produções escritas de contos para o ensino de Matemática; analisar como se configura $\circ$ uso das produções escritas de contos para o ensino de 
Matemática, com vistas à resolução de problemas; averiguar como os alunos sistematizam seus saberes matemáticos a partir da produção escrita de contos.

Este estudo, de abordagem qualitativa, fundamentado nos estudos de Flick (2004), configura-se como uma pesquisa-ação, na qual faz-se importante $\mathrm{o}$ envolvimento do pesquisador durante a investigação (THIOLLENT, 2011). Teve a escola como um cenário de interações e contou com o apoio de professores e demais profissionais da educação para provocar situações desafiadoras em que os alunos sejam capazes de elucidar os saberes matemáticos nas produções textuais dos contos.

Para tanto, tomamos como locus, uma escola municipal, na cidade de Rio Largo, e como sujeitos 35 alunos do $5^{\circ}$ ano dos anos iniciais do Ensino Fundamental, turno vespertino.

Os dados foram produzidos a partir da observação participante, questionário aberto, atividades desenvolvidas, oficinas de leitura e escrita das produções dos contos, pelos alunos.

Neste estudo, trataremos das diferentes compreensões sobre o gênero textual conto, em diálogo com o ensino de Matemática, dos dilemas e desafios da inserção dos contos nas aulas de Matemática, na perspectiva da resolução de problema, a abordagem metodológica utilizada, os resultados, acompanhados das análises e interpretações, bem como a conclusão desta pesquisa.

\section{GÊNERO TEXTUAL CONTO E O ENSINO DE MATEMÁTICA: algumas reflexões}

Agregar o gênero textual às aulas de Matemática é um grande desafio para o professor; de acordo com Smole (2003, p.68), em "[...] atividades desse tipo, os alunos não aprendem primeiro a Matemática para depois aplicar na história, mas exploram a matemática e a história ao mesmo tempo".

Concordamos com Nacarato, Mengali e Passos (2011, p.114), ao afirmarem que 
Abordar a escrita nas aulas de matemática ainda é, para muitos professores das séries iniciais, algo distante da prática pedagógica. É como quebrar paradigma, uma convenção de uma cultura de aula, a qual até então tínhamos como referência. Torna-se, assim, um verdadeiro desafio.

Essa conexão do conto com a Matemática propicia um momento para construir novos saberes ou lançar mão dos já construídos, propicia a cada aluno por em evidência suas experiências, suas perspectivas.

Com o passar dos tempos e o surgimento de novas técnicas e estilos de escrita, a terminologia conto adquiriu um sentido mais amplo que pode ser expresso na língua inglesa como "short story", significando: história curta/ conto breve/ narrativa curta de forma resumida um texto em que os traços se delimitam em uma escrita curta e sua estrutura em prosa.

Conforme Gotlib (1990, p. 12) o conto

Não se refere só ao acontecido. Não tem compromisso com o evento real. Nele, realidade e ficção não tem limites precisos. [...] A esta altura, não importa averiguar se há verdade ou falsidade: o que existe é já a ficção, a arte de inventar um modo de se representar algo.

André Jolles (1874 -1946) afirma que o conto possui "uma forma que permanece através dos tempos, recontada por vários, sem perder sua forma", que se caracteriza como objetiva e fechada, à que possui apenas umas história e um conflito. Além disso, o autor conclui que o conto não pode ser concebido sem seu caráter maravilhoso. Gotlib (1990, p. 18) explica que

E o conto obedece a uma "moral ingênua", que se opõe ao trágico real. Não existe a "ética da ação", mas a "ética do acontecimento": as personagens não fazem o que devem fazer. Os acontecimentos é que acontecem como deveriam acontecer. Este conto é transmitido, oralmente ou por escrito, através dos séculos. Porque pode ser recontado com as "próprias palavras", sem que o seu "fundo" desapareça. Pelo contrário, qualquer um que conte o conto, manterá a sua forma, que é a do conto e não a sua, que é uma forma simples. 
Para Soares (1993, p. 54), o conto é a designação de uma narrativa curta e se diferencia do romance e da novela por características estruturais e pelo tamanho:

Ao invés de representar o desenvolvimento ou o corte na vida das personagens, visando a abarcar a totalidade, o conto aparece como uma amostragem, como um flagrante ou instantâneo, pelo que vemos registrado literariamente um episódio singular e representativo.

Para Abaurre (2007), o conto é uma narrativa curta que apresenta narrador, personagens, enredo, espaço e tempo. Ele deve construir uma história focada no desenvolvimento e na resolução de um conflito básico.

Como toda narrativa existe uma estrutura a ser seguida, conforme 0 quadro 1.

QUADRO 1 - Composição do gênero conto

\begin{tabular}{|c|l|}
\hline Enredo & $\begin{array}{l}\text { A história propriamente dita, na qual os fatos são organizados de } \\
\text { acordo com os acontecimentos. }\end{array}$ \\
\hline Conflito & Envolve o leitor com a história. \\
\hline Clímax & $\begin{array}{l}\text { É o momento culminante da história, ou seja, aquele de maior tensão, } \\
\text { no qual o conflito atinge seu ponto máximo. }\end{array}$ \\
\hline Personagem & Os seres reais ou fictícios envolvidos na história. \\
\hline Tempo & O momento em que tudo acontece. \\
\hline Espaço & O lugar onde se passam os fatos. \\
\hline Desfecho & Solução dos fatos apresentados. \\
\hline
\end{tabular}

Fonte: Elaborado pelos pesquisadores (2018), baseados em Sarmento e Tufano (2004).

É importante observar que a composição do gênero conto apresenta uma estrutura que norteia a sua caracterização, por exemplo: a poesia tem uma estrutura em versos e ritmados. 
Sobre o gênero textual conto destacamos alguns tipos pertinentes, com os quais podemos desenvolver atividades com os alunos do Ensino Fundamental (quadro 2).

QUADRO 2 - Tipos de contos

\begin{tabular}{|c|c|}
\hline Tipos & Definição \\
\hline Encantamento & $\begin{array}{l}\text { É um tipo de conto popular caracterizado pelo elemento } \\
\text { sobrenatural ou fantástico, em que intervêm seres fabulosos, } \\
\text { animais antropomórficos, objetos mágicos, etc. }\end{array}$ \\
\hline Enigma & $\begin{array}{l}\text { Apresenta um crime ou um mistério a ser desvendado. Por esse } \\
\text { motivo, essas histórias, geralmente, apresentam a figura de um } \\
\text { detetive ou de alguém que desempenha o papel de esclarecer o } \\
\text { enigma, tornando-se um herói após desmembrar todo o } \\
\text { "problema". }\end{array}$ \\
\hline Fadas & $\begin{array}{l}\text { Têm natureza espiritual, ética e existencial. Sua origem está ligada à } \\
\text { cultura celta e retratam a história de heróis e heroínas. }\end{array}$ \\
\hline Fantástico & $\begin{array}{l}\text { É uma das formas mais livres de escrever. O conto fantástico é a } \\
\text { construção de um mundo irreal, com situações improváveis e } \\
\text { ações que transpassam a realidade além do humano. }\end{array}$ \\
\hline Jacosos/Populares & $\begin{array}{l}\text { A palavra "Jocoso" significa aquilo tem a função de provocar o riso } \\
\text { principalmente através de gozação e zombaria, sua narrativa gira } \\
\text { em torno de algo engraçado, uma comédia. }\end{array}$ \\
\hline Maravilhosos & $\begin{array}{l}\text { Desenvolvem também num ambiente mágico (animais, gênios, } \\
\text { plantas, objetos mágicos e duendes), sem a presença de fadas. } \\
\text { Considera-se como Conto Maravilhoso toda a situação que ocorre } \\
\text { fora do nosso entendimento da dicotomia espaço/tempo ou } \\
\text { realizado em local vago ou indeterminado na Terra. }\end{array}$ \\
\hline Mistério & A narrativa se estrutura de forma a criar expectativa e suspense. \\
\hline Terror & $\begin{array}{l}\text { É um relato literário ficcional que visa provocar sentimentos de } \\
\text { medo no leitor: a morte, as doenças, os crimes, as catástrofes } \\
\text { naturais, os espíritos e as bestas sobrenaturais. }\end{array}$ \\
\hline
\end{tabular}

Fonte: Elaborado pelos pesquisadores (2018), baseado em Artur Laizo. 
Essas características de cada tipo de conto possibilitaram seu uso para análise dos saberes matemáticos, os quais foram evidenciados nos textos produzidos pelos alunos.

Com base nas características de cada conto, o aluno foi desafiado a desenvolver sua produção textual, a partir dos seus saberes matemáticos que dariam significados às ações, determinando o tempo, isto é, a duração das ações narrativas, entre outros elementos essenciais para situar a história em seu contexto.

Como afirma, Smole (2003, p.67),

Algumas formas de propiciar a relação matemática/língua podem ser encontradas em atividades que envolvem ler, escrever, falar e ouvir sobre matemática e cada um desses aspectos deve engendrar um esforço considerável por parte do professor que conduz o trabalho em sala de aula.

Importante frisar que o gênero conto faz parte do mundo da leitura do aluno, que já tem uma trajetória como conhecedor de alguns contos, como leitor ou como ouvinte. Neste sentido, cabe ao professor, em sua sala de aula, oportunizar esses momentos de leitura, proporcionando aos alunos o reconhecimento da função social dos textos e os usos em diferentes práticas sociais, visando ao desenvolvimento de saberes matemáticos.

Quando pensamos numa atividade que sugere a produção escrita do conto, algumas orientações são importantes e precisam ser consideradas: encontrar um tema simples sem muita complexidade, buscar inspiração no cotidiano, os personagens precisam ser direcionados a uma função, seus gostos, hábitos, pontos de vista, etc.

O ensino da Matemática não deve se restringir apenas a conceitos e algoritmos, isto é, ao que diz respeito à memorização, pois isso não garante que o aluno saberá resolver situações problemas propostas em futuras avaliações. Desse modo, o aluno precisa ser desafiado a conhecer o novo e adquirir autonomia para resolver problemas.

Nessa concepção, segundo Ortega (2011, p. 15) 
Há uma ideia relativamente aceita entre os educadores, que um ensino de Matemática em que os alunos não consigam compreender o sentido do que está sendo ensinado, baseado na repetição de algoritmos, na memorização de fatos matemáticos fragmentos e descontextualizados, não tem contribuído para a aquisição e uso de noções matemáticas de forma adequada e com compreensão do significado e alcance das possibilidades desse conhecimento. Nessa perspectiva, considera-se que a formação do professor é elemento essencial para que essas capacidades sejam desenvolvidas de modo satisfatório.

Compreendemos a importância do ambiente escolar para a construção e sistematização do conhecimento matemático, e o professor como corresponsável para que seu aluno desenvolva aprendizagens necessárias ao exercício de sua aplicabilidade no seu cotidiano.

O papel do professor é indispensável, pois é a ele que cabe a tarefa de planejar, participar, instigar as discussões, acompanhar e analisar a construção do conhecimento através da participação individualizada e coletiva dos alunos nos espaços de interação disponibilizados no ambiente, tendo a capacidade de construir novos objetos de conhecimento, a visualização concreta de elementos abstratos, o compartilhamento de experiências e emoções de maneira informal e altamente personalizável (OLIVEIRA, 2018, p.12).

Essa perspectiva de enveredar por caminhos em que se articulem saberes da Língua Portuguesa ao saber matemático, é o que nos faz pensar a possibilidade de agregar aos saberes matemáticos as experiências vividas ao compartilhamento dos saberes abstratos. Cabe ao professor pensar a forma como isso ocorrerá para que não seja apenas mais um planejamento, mas que atenda as exigências que serão enfrentadas em algum momento da vida do indivíduo.

Por esta razão, o nosso foco é o protagonismo do aluno, visando à sistematização dos saberes matemáticos a serem elencados em uma produção escrita, contemplando áreas que são importantes para compreensão de outros saberes. 


\title{
INSERÇÃO DOS CONTOS NAS AULAS DE MATEMÁTICA, NA PERSPECTIVA DA RESOLUÇÃO DE PROBLEMA
}

Comumente, o ser humano faz uso da resolução de problemas, partindo do mais simples aos mais complexos. É um equívoco pensar que essa ação é prioridade da área de Matemática, já que a resolução de problemas matemáticos é significativa para a educação, de modo geral, por desenvolver o espírito de curiosidade e criticidade dos envolvidos, e criar situações reais em sala de aula, além das possibilidades da descoberta do inédito. A resolução de problemas é uma metodologia interessante e, quando bem trabalhada, pode tornar-se bastante satisfatória no ensino da Matemática, como afirmam Rêgo e Paiva (2009, p. 245),

\begin{abstract}
A importância da Resolução de Problemas vai muito além da Matemática, pois sua prática pode contribuir para 0 desenvolvimento das potencialidades cognitivas de nossos alunos. Para muitos educadores, um dos principais objetivos da educação deve ser 0 de preparar 0 aluno para resolver problemas. Essa competência, em um mundo dinâmico e com o volume de informações que se tem hoje, pode fazer a diferença, seja para atuação no mercado de trabalho como também para o pleno exercício da cidadania.
\end{abstract}

Corroborando o que dizem as autoras, a resolução de problemas pode ser trabalhada em qualquer área do conhecimento, pois o ato de resolver problemas é uma atividade que está presente na vida cotidiana das pessoas e, geralmente, requer o uso de estratégias de resolução.

Na Matemática, a aprendizagem dessas estratégias colabora para o desenvolvimento do raciocínio lógico dos alunos e os ajuda a resolver em outros contextos e a entender, em seu cotidiano, que ações matemáticas serão significativas para determinadas soluções.

A concepção de resolução de problemas, numa perspectiva metodológica corresponde a uma forma de organizar o ensino que envolve mais que aspecto metodológico, inclui o entendimento do que é ensinar, e consequentemente, do que é aprender.

Analisar a Resolução de Problemas como uma perspectiva metodológica a serviço do ensino e da aprendizagem de

Revista Exitus, Santarém/PA, Vol. 10, p. 01-30, e020066, 2020. 
matemática amplia a visão puramente metodológica e derruba a questão da grande dificuldade que alunos e professores enfrentam quando se propõe a Resolução de Problemas nas aulas de matemática. A utilização de recursos da comunicação pode resolver ou fazer com que não existam essas dificuldades (DINIZ; SMOLE, 2001, p.87).

Assim, para essas autoras, a resolução de problemas, numa perspectiva metodológica, baseia-se na proposição e enfrentamento do que chamamos de situação problema, definindo problema como situação sem solução imediata e que exige que o aluno combine os conhecimentos adquiridos, decidindo, assim, pela forma de usá-los em busca da solução. Dessa forma, rompe-se com a visão limitada de problemas que podem ser chamados de convencionais e que são os tradicionalmente propostos aos alunos.

Dentre as diversas formas de se trabalhar a resolução de problemas, nesta investigação, escolhemos a produção de um texto a partir de um problema. Durante a produção escrita, os alunos desenvolveram uma situação conflito que consistiu em apresentar seus conhecimentos matemáticos ao longo da escrita e que foram evidenciados na contextualização dos seus contos.

Segundo Panizza (2006, p.51.),

É conveniente levar em conta que o ensino tradicional se centra com frequência, basicamente, nos aspectos sintáticos, mas a partir de um enfoque que limita o ensino a uma reprodução de métodos, sem se ocupar da construção do sentido em nenhum dos níveis.

Vale ressaltar que o professor pode analisar o nível em que os alunos se encontram, para que possam ser incentivados a buscar soluções em que possam raciocinar e de forma ampla, desenvolver habilidades que, por muitas vezes, nas aulas de Matemática não são oportunizadas, apenas trabalhando de forma abstrata com fórmulas estabelecidas, sem contextualização com o seu cotidiano.

Segundo Smole et al. (1996, p. 30),

Através da conexão entre a literatura e Matemática, o professor pode criar situações na sala de aula que encorajem os alunos a 
compreenderem e se familiarizarem mais com a linguagem matemática, estabelecendo ligações cognitivas entre a linguagem materna, conceitos da vida real e a linguagem matemática formal, dando oportunidades para eles escreverem e falarem sobre 0 vocabulário matemático, além de desenvolverem habilidades de formação e resolução de problemas enquanto desenvolvem noções e conceitos matemáticos.

Além disso, há possibilidades para atividades interdisciplinares que podem fazer parte do processo, já que, para solucionar problemas de diversas áreas educacionais, utilizam-se conhecimentos matemáticos.

Fazer uso de um problema para estruturar um conto torna possível ao aluno desenvolver habilidades que consistem em resolver problemas-padrão com a aplicação direta de um ou mais algoritmos.

Além disso, a produção de contos, na perspectiva da resolução de problemas, permite que o aluno explore fatos e lugares, estabelecendo relações com os personagens, com a finalidade de solucionar os conflitos, que surgem na sua escrita. Portanto, é importante proporcionar aos alunos desafios que os levem a perceber que a produção de contos é uma das possibilidades de se criar situações problemas, fazendo uso dos saberes matemáticos.

Por isso, consideramos que a leitura é o ponto de partida para a exploração de saberes matemáticos, e salientamos que o professor precisa refletir sobre a relação entre os assuntos que ele aborda e o que é de interesse dos alunos focando em suas ações no mundo social. O trabalho com leitura envolve um processo dialógico, no qual um leitor ativo interage com o texto para compreendê-lo, garantindo saberes linguísticos que poderão servir para desenvolver habilidades de leitura, escrita, compreensão e interpretação de problemas matemáticos.

A Base Nacional Comum Curricular (BNCC) descreve que,

O objetivo norteador do ensino de Língua Portuguesa é garantir a todos os alunos o acesso aos saberes linguísticos necessários para a participação social e o exercício da cidadania, pois é por meio da língua que o ser humano pensa, comunica-se, tem acesso à informação, expressa e defende pontos de vista, partilha ou constrói visões de mundo e produz conhecimento (BRASIL, 2018, p. 68). 
A leitura é uma das práticas de linguagem descrita na BNCC (BRASIL, 2018, p.71), que compreende, portanto,

\begin{abstract}
O desenvolvimento de habilidades de compreensão e interpretação de textos verbais e multimodais e, ainda, a identificação de gêneros textuais, que esclarecem a contextualização dos textos na situação comunicativa, o que é essencial para compreendê-los. São também constituintes essenciais desse eixo, por sua relevância para a compreensão e interpretação de textos, o desenvolvimento da fluência e o enriquecimento do vocabulário.
\end{abstract}

De acordo com Solé (1998, p.22), a leitura "é um instrumento necessário para a realização de novas aprendizagens. É um processo de interação entre o leitor e o texto, no qual o leitor constrói o significado e o entendimento do texto", não se limitando à decifração de signos.

A leitura e produção textual do gênero conto já faz parte da estrutura de conceitos a serem trabalhados na escola, atualmente com a aplicação das orientações da BNCC, que norteiam as habilidades e competências a serem alcançados pelos alunos de acordo com os conhecimentos desenvolvidos em sala de aula. Somado à resolução de problemas como metodologia de ensino, o conto pode ajudar o aluno a atribuir um significado à aprendizagem da matemática, uma vez que, diante do problema, ele precisa utilizar saberes já construídos para formular hipóteses e alternativas de solução da questão proposta pelo professor.

Segundo Smole, Diniz e Cândido (2000, p.19), a resolução de problema

[...] é uma perspectiva metodológica através da qual os alunos são envolvidos em fazer matemática, isto é, eles se tornam capazes de formular e resolver por si questões matemáticas e, pela possibilidade de questionar e levantar hipótese, adquirem, relacionam e aplicam conceitos matemáticos.

Por meio da resolução de problema, a Matemática pode ser reconhecida como uma área de conhecimento acessível a todos os alunos, sendo (re) significada a cada experiência de aprendizagem. Entretanto, não basta apenas realizar as atividades propostas nos livros didáticos sem relacioná-las com as atividades humanas; é preciso integrar tais conhecimentos ao cotidiano dos alunos, pois poderão servir para a 
resolução de situações problemas com as quais os sujeitos se deparem em algum momento da vida.

\section{(ENTRE)LAÇAMENTO DA/NA PESQUISA: caminhos metodológicos}

A pesquisa como um processo criativo deve ser identificada pela exploração e identificação de múltiplas perspectivas que buscam a compreensão do fenômeno, sejam elas positivistas, construtivistas, interacionistas ou outras, implicando habilidades metodológicas mínimas em termos de construção de propostas dotadas de alguma cientificidade, em particular, a capacidade de argumentar.

Partindo desse princípio, esta investigação, de base qualitativa (FLICK, 2004), ocorreu em um cenário natural, a partir das expressões e atividades das pessoas, em seus contextos locais, buscando conhecer o que é dito e o que não é dito, quem são os sujeitos que falam ou não falam; como as situações são vividas e percebidas, enquanto processo com o qual se definem e se redefinem, constantemente, todas as decisões no âmbito do campo de pesquisa, considerando este como o cenário social.

Optamos pela metodologia da pesquisa-ação (THIOLLENT, 2011), visto que está é uma das formas de investigação-ação para a melhoria da prática e pesquisa, a qual oportuniza a transformação do ambiente escolar por meio da ação-prática. Nesse método de investigação, faz-se necessária a intervenção do pesquisador para analisar o problema de forma participativa e ativa.

Esta pesquisa se desenvolveu em uma escola pública da rede municipal de Rio Largo-AL. O município de Rio Largo está localizado na região leste do Estado de Alagoas, limitando-se a norte com os municípios de Murici e Messias, a sul com Satuba e Pilar, a leste com Maceió e a oeste com Atalaia. Tal escola fica localizada na zona urbana do município e atende turmas do $1^{\circ}$ ao $5^{\circ}$ ano do Ensino Fundamental.

Participaram deste estudo 35 (trinta e cinco) alunos do $5^{\circ}$ ano, sendo 20 (vinte) meninas e 15 (quinze) meninos do Ensino Fundamental, do turno vespertino. 
Os instrumentos, descritos no quadro 3, foram escolhidos com o objetivo de se criar dados para análise e interpretação, visando atender os objetivos traçados para este estudo.

QUADRO 3 - Instrumentos utilizados para a coleta de dados desta pesquisa

\begin{tabular}{|l|l|}
\hline Observação participante & $\begin{array}{l}\text { Foram observados o envolvimento e } \\
\text { escrita dos alunos ao longo das atividades } \\
\text { desenvolvidas de leitura produção } \\
\text { textual do conto nas aulas de } \\
\text { Matemática. }\end{array}$ \\
\hline Questionário aberto & $\begin{array}{l}\text { Foi aplicado um questionário aberto com } \\
\text { objetivo de apreender o ponto de vista } \\
\text { dos alunos acerca da disciplina de } \\
\text { Matemática. }\end{array}$ \\
\hline Atividades de Matemática & $\begin{array}{l}\text { Foram aplicadas atividades de resolução } \\
\text { de problemas com situações que } \\
\text { envolvessem as quatro operações } \\
\text { matemáticas. }\end{array}$ \\
\hline Vídeos, fotografias e diário de campo & $\begin{array}{l}\text { Vídeos, fotografias e diário de campo } \\
\text { foram utilizados para os registros durante } \\
\text { das observações, durante a realização } \\
\text { das oficinas de leitura e das produções } \\
\text { textuais. }\end{array}$ \\
\hline
\end{tabular}

Fonte: Elaborado pelos pesquisadores (2018).

A última etapa da construção de dados foi a produção dos contos pelos alunos, que organizados em 5 equipes, receberam, através de sorteio, o problema a ser resolvido (quadro 4) e, em seguida, sua resolução foi ilustrada de acordo com o enredo criado pelas equipes, buscando evidenciar alguns saberes matemáticos.

QUADRO 4 - Produção de contos para resolução de situação problemas

\begin{tabular}{|c|c|c|c|}
\hline Equipe & Tipo de conto & Título & Problema \\
\hline 1 & $\begin{array}{c}\text { Conto } \\
\text { encantamento }\end{array}$ & $\begin{array}{c}\text { Noite de } \\
\text { Halloween }\end{array}$ & $\begin{array}{c}\text { Uma criança tinha 13 ovos de } \\
\text { páscoa. Ganhou mais 7 ovos de } \\
\text { páscoa. Quantos ovos de páscoa ela }\end{array}$ \\
\hline
\end{tabular}

Revista Exitus, Santarém/PA, Vol. 10, p. 01-30, e020066, 2020. 


\begin{tabular}{|c|c|c|c|}
\hline & & & tem agora? \\
\hline 2 & $\begin{array}{c}\text { Conto } \\
\text { maravilhosos }\end{array}$ & $\begin{array}{l}\text { Era uma vez } \\
\text { um cachorro }\end{array}$ & $2018-1879=$ \\
\hline 3 & Conto de fadas & $\begin{array}{l}\text { A família das } \\
\text { fadas }\end{array}$ & $\begin{array}{l}\text { Em uma família havia } 5 \text { irmãs uma } \\
\text { delas ficou doente. Quantas irmãs } \\
\text { estavam saudáveis? }\end{array}$ \\
\hline 4 & Conto de mistério & $\begin{array}{l}\text { O } \\
\text { acampamento } \\
\text { assombrado }\end{array}$ & $\begin{array}{l}\text { A diretora de uma escola resolveu } \\
\text { levar os alunos ao um acampamento, } \\
\text { só que ela precisará preencher o } \\
\text { formulário com as seguintes } \\
\text { perguntas: Quantos professores irão } \\
\text { para o acampamento. Quantos } \\
\text { alunos irão participar? Que horas sairá } \\
\text { da escola? Que horas voltará? }\end{array}$ \\
\hline 5 & $\begin{array}{c}\text { Contos } \\
\text { populares/jacosos }\end{array}$ & O mentiroso & $\begin{array}{c}\text { Uma telefonista tem que fazer } 7 \\
\text { ligações para clientes, se cada } \\
\text { cliente retornar a ligação } 3 \text { vezes. } \\
\text { Qual o total de ligações da } \\
\text { telefonista com o retorno das ligações } \\
\text { dos clientes para a telefonistas? }\end{array}$ \\
\hline
\end{tabular}

Fonte: Elaborado pelos pesquisadores (2018).

Salientamos que, durante as etapas, os sujeitos eram instigados a falar sobre os contos produzidos, tanto em relação à parte escrita quanto em relação às ilustrações, na intenção de fazê-los refletir sobre o porquê das ações no conto por eles criado. Conforme Smole, Diniz e Cândido (2000, p.17)

(...) sempre que pedimos a uma criança ou a um grupo para dizer o que fizeram e por fizeram ou quando solicitamos que verbalizem os procedimentos que adotaram, justificando-os ou comentem o que escreveram, representaram ou esquematizaram, relatando as etapas de sua pesquisa, estamos permitindo que modifiquem conhecimentos prévios e construam novos significados para as ideias matemáticas. Dessa forma, simultaneamente, os alunos refletem sobre os conceitos e os processos envolvidos na atividade proposta, apropriam-se delas, revisam o que não entenderam, ampliam o que compreenderam e, ainda, explicam suas dúvidas e dificuldades.

Interessaram-nos, para fins de análise e interpretação, os resultados da interação entre os sujeitos na resolução de alguns problemas que emergiam 
durante a execução das etapas. Enfim, com as produções dos contos dos alunos finalizadas, analisamos os saberes matemáticos evidenciados e refletimos sobre as possibilidades da produção escrita dos contos para o processo de ensino e aprendizagem em Matemática.

\section{PRODUÇÃO ESCRITA DOS CONTOS: evidenciando saberes matemáticos}

A produção de textos, nas aulas de Matemática, é uma atividade desafiadora, para aqueles que ainda pensam que a Matemática é algo mecânico ou até mesmo aplicação de fórmulas para a resolução de um problema.

As oficinas de leitura e escrita proporcionaram aos alunos do $5^{\circ}$ ano do Ensino Fundamental, tanto no ato leitura como na escrita, destacar saberes matemáticos que estão explícitos e implícitos na produção textual do aluno. Dos dos 5 tipos de contos produzidos pelos grupos, trazemos aqui a análise do conto "Uma noite de Halloween", classificado como conto de encantamento.

O problema apresentado pelo referido conto foi o seguinte: "Uma criança tinha 13 ovos de páscoa. Ganhou mais 7. Quantos ovos ela tem agora?". Ao analisarmos a figura 1, percebemos a ampliação e redução de personagens arquitetadas por uma das equipes que nos remete aos conceitos de longe e perto; observamos, ainda, os segmentos de retas paralelas e curvas para a formação de imagens, que caracterizam o cenário.

Figura 1 - Primeira ilustração do conto "Uma noite de halloween"

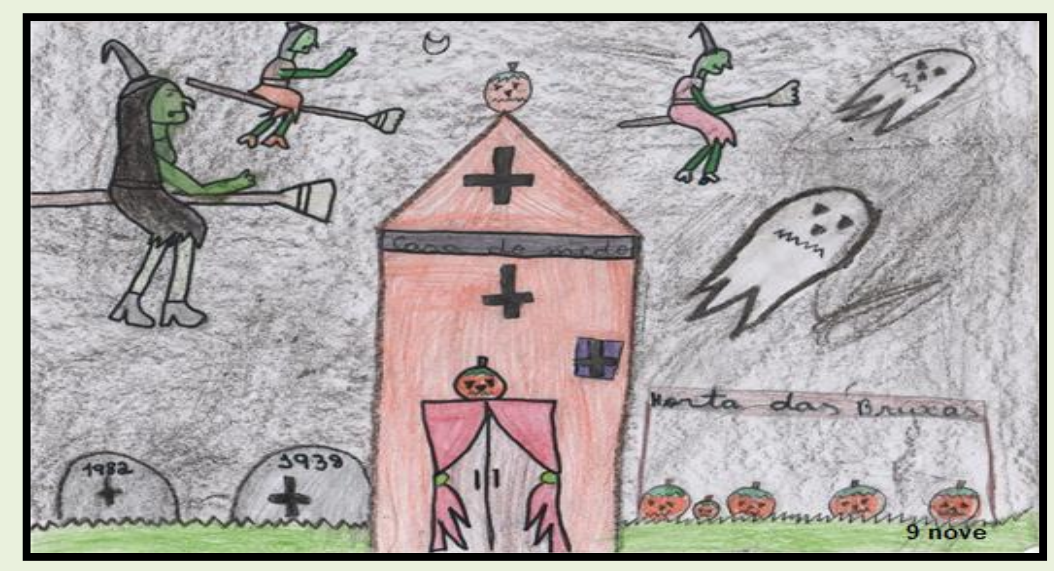

Fonte: Dados da pesquisa (2018). 
As formas geométricas presentes na figura 1, nos levam a interpretar que os alunos aprenderam que os objetos têm uma forma e ocupam um determinado espaço, o que pode ser observados através das formas utilizadas por eles: triângulo, retângulo, círculos, semi-circulos (SMOLE, 1996).

Percebe-se, ainda, na imagem, a aplicação dos números indoarábico para indicar marcação de tempo como está ilustrado na lápide. Ainda na figura 1, percebemos que os alunos misturam desenhos e sinais matemáticos; pois demonstram conhecer a importância de tais conteúdos, associando o abstrato a uma determinada realidade, com a consciência da sua importância para o aprendizado matemático.

A partir da ilustração produzida, questionamos os alunos sobre a contribuição desta estratégia de aprendizagem, como recurso didático e alternativo para identificar quais saberes matemáticos são revelados, e os sujeitos assim responderam:

[A3] Ajuda [a experiência da ilustração dos contos], ajuda muito. A gente (os alunos) conversou muito sobre as formas geométricas, sobre o sistema de numeração decimal, sobre as figuras que foram cada desenho.

[A15] Foi possível compreender que a Matemática está presente em várias coisas do nosso cotidiano, como por exemplo: os números que são identificados em diversos lugares, nas placas, no nosso documento, no calçado, etc.

[A20] Com certeza [contribuiu] porque a gente escrevendo e desenha, a gente vai ver a nossa capacidade de fazer uma ilustração com saberes matemáticos que já carregamos e vai também desenvolvendo um pouco a interpretação matemática, porque eu melhorei muito o gosto pela disciplina.

Outra situação que analisamos na ilustração foi a composição das cores, muito importante para enfatizar o período noturno em que acontece o fato narrado pelos alunos; fizeram uso das cores escuras, de cores quentes para destacar alguns elementos, como as abóboras, ao lado da "casa do medo" para caracterizar o contexto e temática para um conto de encantamento. Também podemos destacar a textura presente na pintura: observamos que o fundo da ilustração foi pintado sobre uma estrutura que o deixou com uma textura diferenciada. 
No conto produzido por uma das equipes (Equipe 1), podemos evidenciar alguns saberes matemáticos; por exemplo, na terceira linha do conto (figura 2), quando os alunos escrevem "as 0:00 noite retornavam as bruxas", evidenciam o conhecimento de medidas de tempo, compreendendo as unidades temáticas de grandezas e medidas.

Figura 2 - Fragmento da $3^{\circ}$ linha do conto "Uma noite de hallowen"

\section{3 is 00:00 naite Retarnaliom as brewcos}

Fonte: Dados da pesquisa (2018).

Em outro fragmento podemos destacar a seguinte descrição: "calda de morango de 1 l". A noção de medida de capacidade é demonstrada quando evidenciam um conhecimento sobre as unidades de medida que tratam de líquidos, nesse caso, usando o litro para medir a calda de morango.

Observamos que esta equipe fez uso da letra inicial e minúscula da palavra litro, representação correta para esta medida de capacidade; da mesma forma que escreve a palavra "muitas" denotando uma quantidade de balas maior que uma unidade, conforme a figura 3 .

Figura 3 - Fragmento da $8^{a}$ linha do conto "Uma noite de hallowen" do conto da Equipe 1

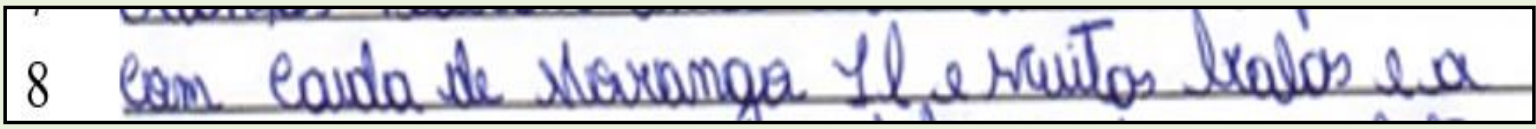

Fonte: Dados da pesquisa (2018).

Na figura 4, observamos a presença do paralelismo representado pelas retas equidistantes no cabo da vossoura, na borda da casa, nas listras desenhadas na porta, no desenho das estrelas, enfim, um cenário constituído de elementos da natureza, os quais evidenciam que o conto traz uma história que ocorreu no período noturno: as estrelas, a lua, os morcegos. 
Figura 4 - Segunda ilustração e escrita do conto "Uma noite de halloween"

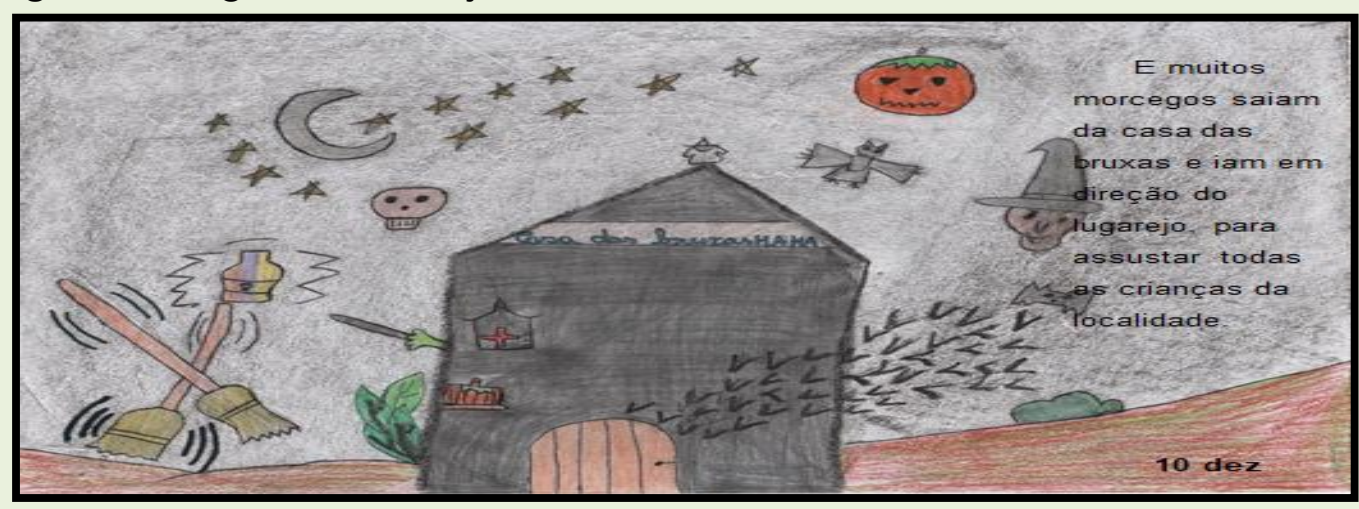

Fonte: Dados da pesquisa (2018).

Quando os alunos descrevem, "muitos morcegos", eles chamam a atenção para os leitores, a preocupação com o cotidiano da cena, explicitando um pouco de sua realidade, a qual se caracteriza abundância, a partir de uma relação de conhecimento da vida cotidiana através das ilustrações (PANIZZA, 2006).

Nessa cena, vislumbramos o texto nas formas visual e verbal que é a presença do texto digitado e da escrita cursiva no próprio desenho, como no caso do letreiro "Casa das bruxas há há"; objetos que estão afastados do solo, no caso as vassouras, para dar a ideia de que estão voando, e a utilização de sinais representativos da magia.

À mão livre, os alunos traçam segmentos de retas que formam ângulos, surgindo daí polígonos fechados, considerados como figuras geométricas planas, como é o caso da composição do desenho da casa, o cone, no chapéu da caveira e na abóbora, que pode ser representada por um círculo.

Em se tratando do processo de figuras planas e seus elementos, mesmo existindo recursos didáticos alternativos, nem todos os alunos envolvidos se adaptarão a este ou aquele recurso no seu processo de aprendizagem. Nesse sentido, a aluna [A32] expressa sua dificuldade quanto à utilização da produção escrita dos contos e suas ilustrações durante as aulas de Matemática. Observem:

(...) Na explicação do professor, com o livro você entende melhor do que nas aulas de Matemática com este recurso. Tá ali, falou, falou, 
mas por mais que você preste atenção, você sempre vai aprender alguma coisa. Esse tipo de atividade eu tenho dificuldade. Agora, se for no livro ou na resolução de problemas não.

Percebemos que a aluna expressa sua dificuldade em utilizar este recurso didático no ambiente escolar em prol de suas aprendizagens. Para alguns alunos, a ação da leitura do livro ou a escrita matemática no quadro são recursos pedagógicos extremamente necessários ao seu processo de aprendizagem, comprovando que o professor necessita mediar a utilização do livro de modo a facilitar a aprendizagem em Matemática (NACARATO; MENGALI; PASSOS, 2011).

Compreendemos que os sujeitos autores dos contos, em processo de aprendizagem, apresentam peculiaridades, dificuldades e potencialidades. São alunos que esperam no retorno à escola, valorização e autoestima e que possuem um imenso potencial para reconstruir saberes em Matemática, pois são sujeitos de conhecimento e de aprendizagens.

Na figura 5, uma outra equipe (equipe 2), observamos que no texto escrito, noções de grandezes e medidas foram apresentadas a partir do momento que citam "1000 litros" e "dezenas de pães"; a ideia também de Sistema de Numeração Decimal quando escrevem "milhares de balas" e "centenas de barras de chocolates" apoiando-se em saberes já estabelecidos pela linguagem utilizada. E para representar os pirulitos fizeram uso de espirais, e no formato quadriculado representaram as barras de chocolate.

Figura 5 - Terceira ilustração e escrita do conto "Uma noite de halloween"

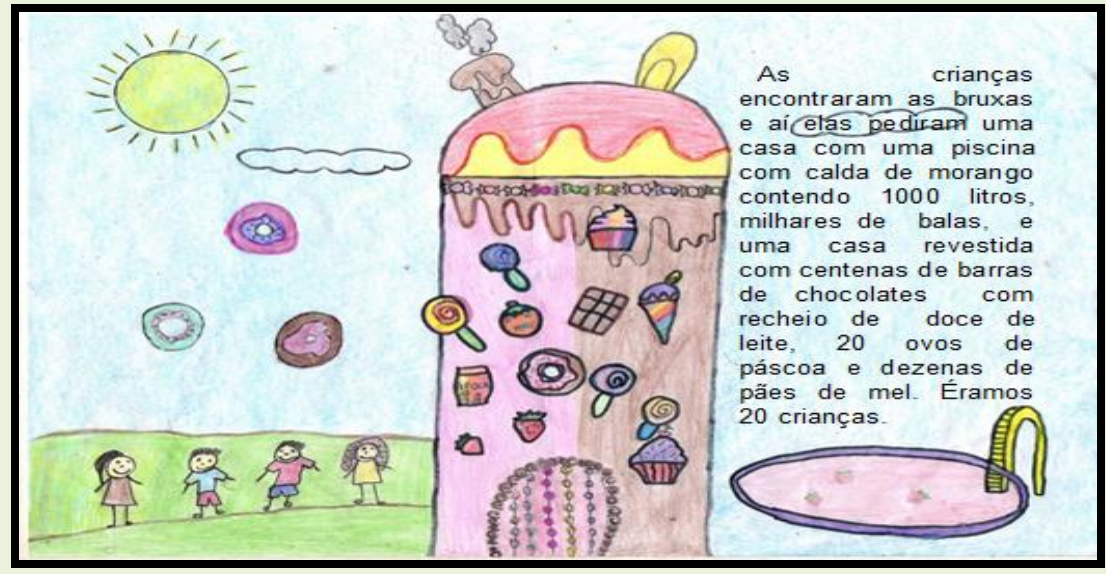

Fonte: Dados da pesquisa (2018). 
A ideia de lateralidade também é visível na ilustração acima, quando as crianças são apresentadas uma do lado da outra, sendo possível trabalhar o conceito de direita e esquerda, em cima ou embaixo e em frente ou atrás.

Esse encantamento presente nesta cena faz até imaginar que algo sombrio esta para acontecer. Eles exploram a luz, e a alegria de representada nas cores e formas.

Fica evidente que as formas geométricas não estão presentes apenas nos objetos que nos cercam, mas no que consumimos; podemos citar, por exemplo: casquinha de sorvete, no formato de cone, pirulitos em forma de círculos e suas pinturas em espirais.

Na figura 6, a bruxa que está localizada no topo da casa e em tamanho reduzido dando a ilusão de distanciamento. As estrelas desenhadas a partir da sobreposição de triângulos, representam os corpos celestes, que estão dispostos na galáxia e que são visualizados no céu durante o período noturno.

Figura 6 - Quinta ilustração do conto "Uma noite de halloween"

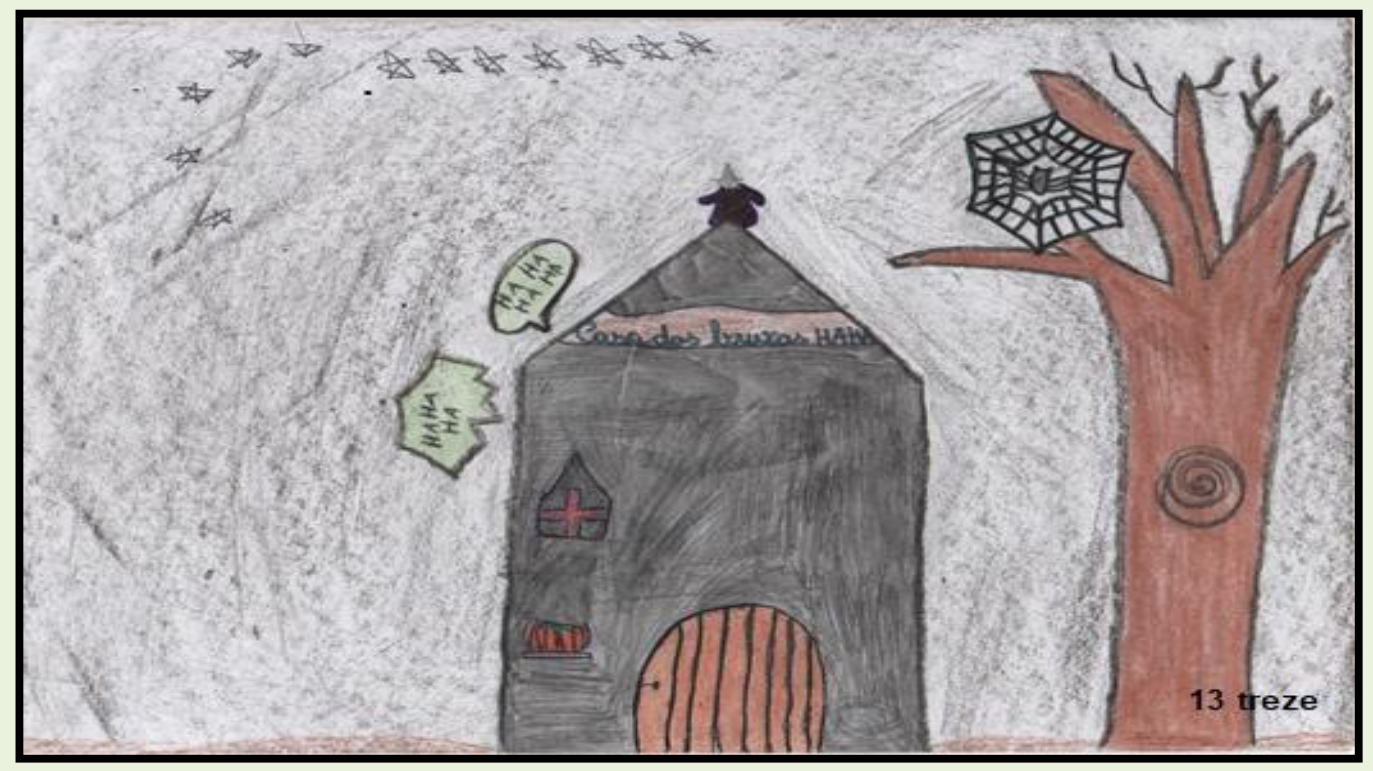

Fonte: Dados da pesquisa (2018).

Outro aspecto a ser observado é o destaque que os alunos dão as imagens, fazendo o contorno da árvore, da casa, da janela e da porta. Tal 
ação pode revelar que o aluno construiu um entendimento sobre a disposição dos objetos dentro de um ambiente.

A localização dos objetos e seres se dá numa perspectiva em que o leitor/observador poderá visualizar as imagens na posição frontal. Por exemplo, a localização da árvore revela o saber de lateralidade, tendo em vista que a lateralidade é a manifestação de um predomínio motor relacionado com as partes do corpo que integram suas metades direita e esquerda, predomínio este vinculado ao processo sensório-motor de um dos hemisférios cerebrais (ORTEGA, 2011).

$\mathrm{Na}$ figura 7, vislumbramos elementos complexos em relação aos tamanhos e formatos diferenciados das garrafas, o relógio de pêndulo e as numerações em algarismos romanos; as formas geométricas que foram usadas para a construção do gato, do armário, do barril; a representação do piso.

Figura 7 - Sexta ilustração do conto "Uma noite de halloween"

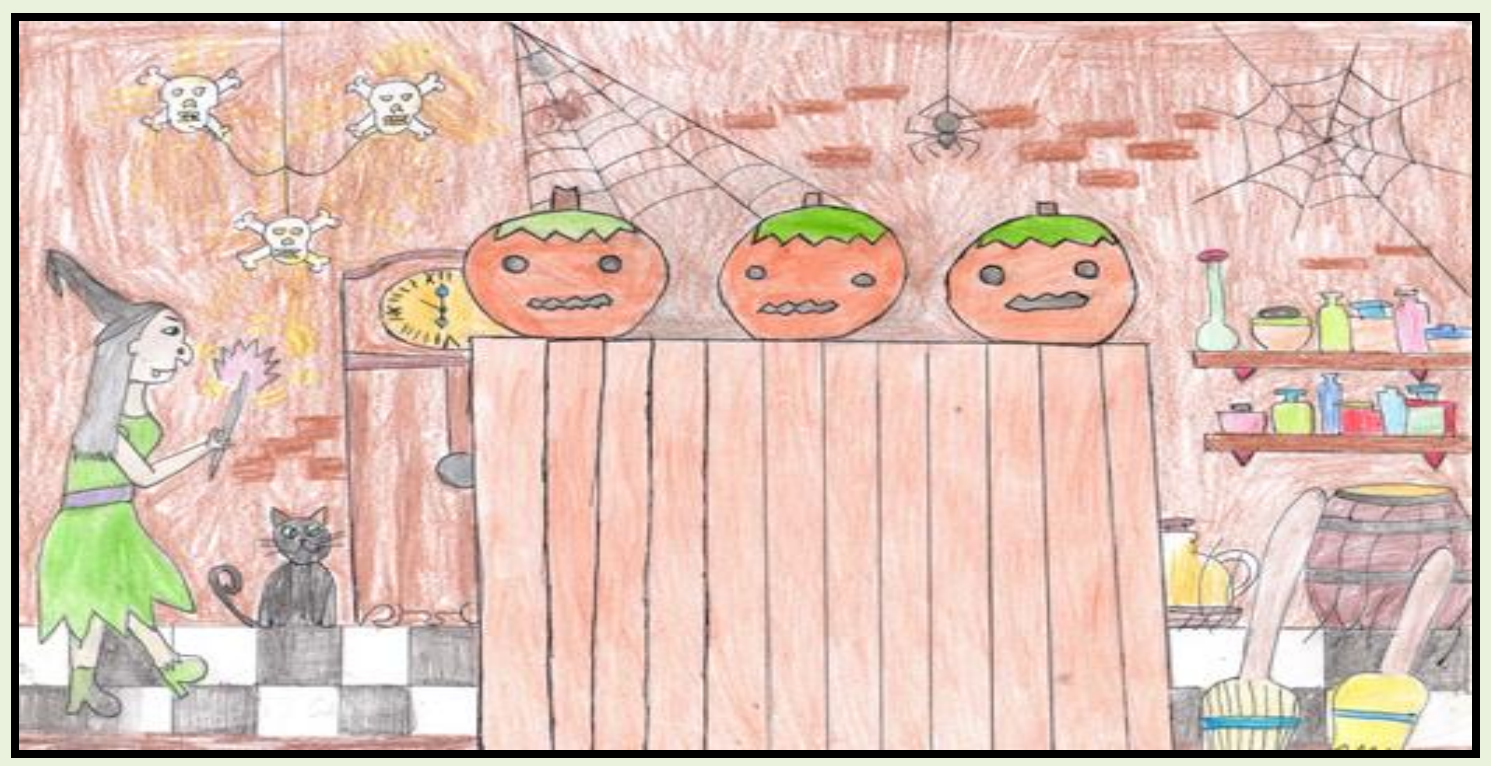

Fonte: Dados da pesquisa (2018).

As linhas que representam as teias de aranha partem de um ponto fixo, gerando o conceito de retas paralelas, retas que não se cruzam, e em outro desenho retas perpendiculares, retas que se cruzam em um único ponto e formam um ângulo de $90^{\circ}$; do mesmo jeito a transparência dos 
tijolos de forma alternada com formato retangular, evidenciando assim, que existe uma relação da Matemática com elementos da natureza, do cotidiano (RÊGO; PAIVA, 2009).

Os alunos combinaram cores, intensificando tons mais escuros e mais claros, para destacar alguns elementos da cena em questão. Isso é observado nos tijolos, na abóbora, no chapéu da bruxa e em outros utensílios.

Percebemos a combinação de formas que se agregam para criar novos formatos, quando eles se utilizam de quadriláteros e círculos para dar forma ao relógio, por exemplo.

Nessa imagem, interpretamos que os saberes matemáticos a respeito de formas geométricas, fruto de suas experiências de vida e também ressignificados a partir das ilustrações do conto, e nas atividades desenvolvidas no contexto de sala de aula, constituem-se em aspectos relevantes da estrutura de seus conhecimentos no tocante, a geometria plana (SMOLE, 1996).

Na figura 8, a maneira como eles dispuseram as árvores, de forma perpendicular alterando do maior para o menor, dá a ilusão de distanciamento, de perto e de longe.

Figura 8 - Sétima ilustração do conto "Uma noite de halloween"

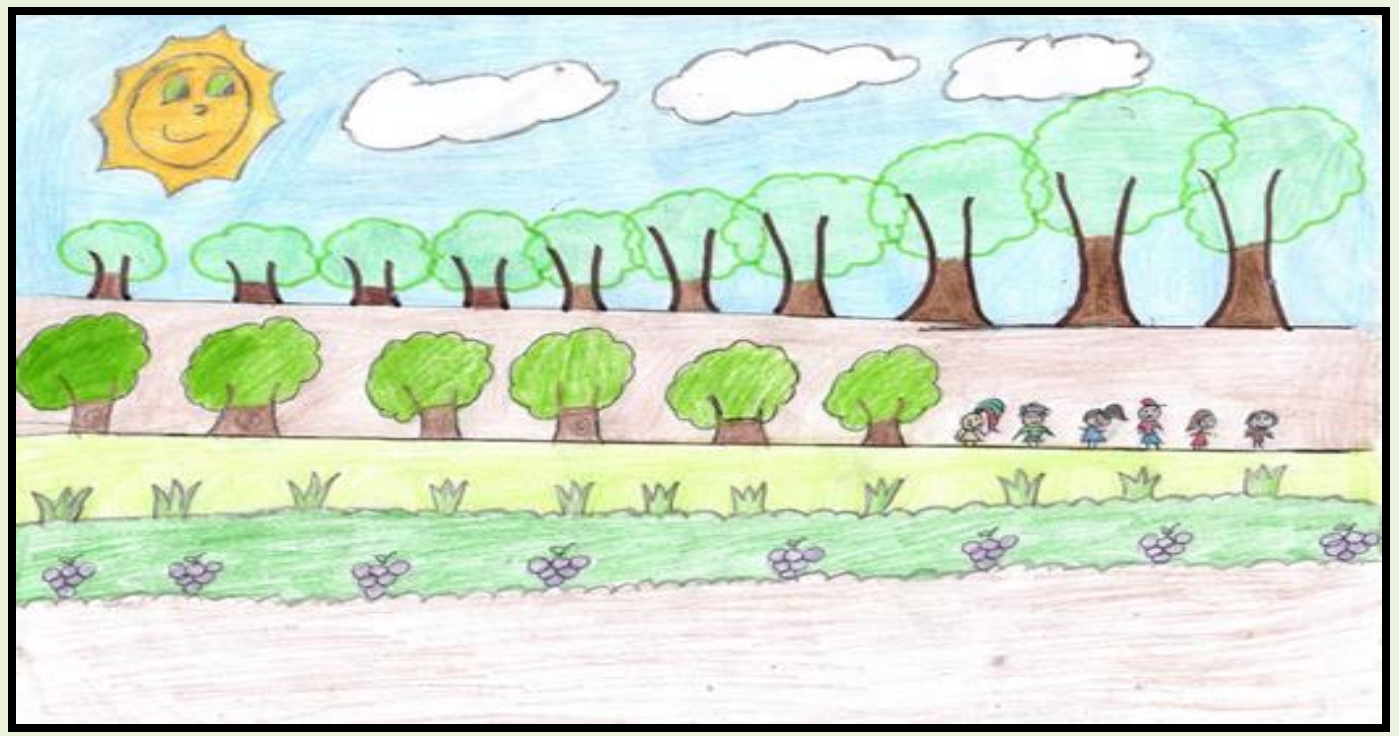

Fonte: Dados da pesquisa (2018). 
Assim, o estudo da geometria plana possibilita uma abordagem crítica da realidade, relacionando o conteúdo com situações concretas, fazendo com que o aluno parta do concreto para mais tarde chegar a situações mais abstratas, pois o professor deve dar tempo para o aluno descobrir algumas relações, exercendo o papel de observador e mediador percebendo o momento para intervir, questionando os alunos e assim criando com eles os conceitos pré definidos (DINIZ; SMOLE, 2001).

Outra questão a ser ressaltada são as divisões dos planos horizontais que se diferenciam pelas cores aplicadas. As figuras geométricas do tipo: triângulo, retângulo, círculos são elementos constituintes para a composição da figura 9. As imagens fazem com que percebamos que o sujeito faz uso tridimensional quando desenha a placa que dá ideia de profundidade.

Figura 9 - Oitava ilustração e continuação da escrita do conto "Uma noite de halloween"

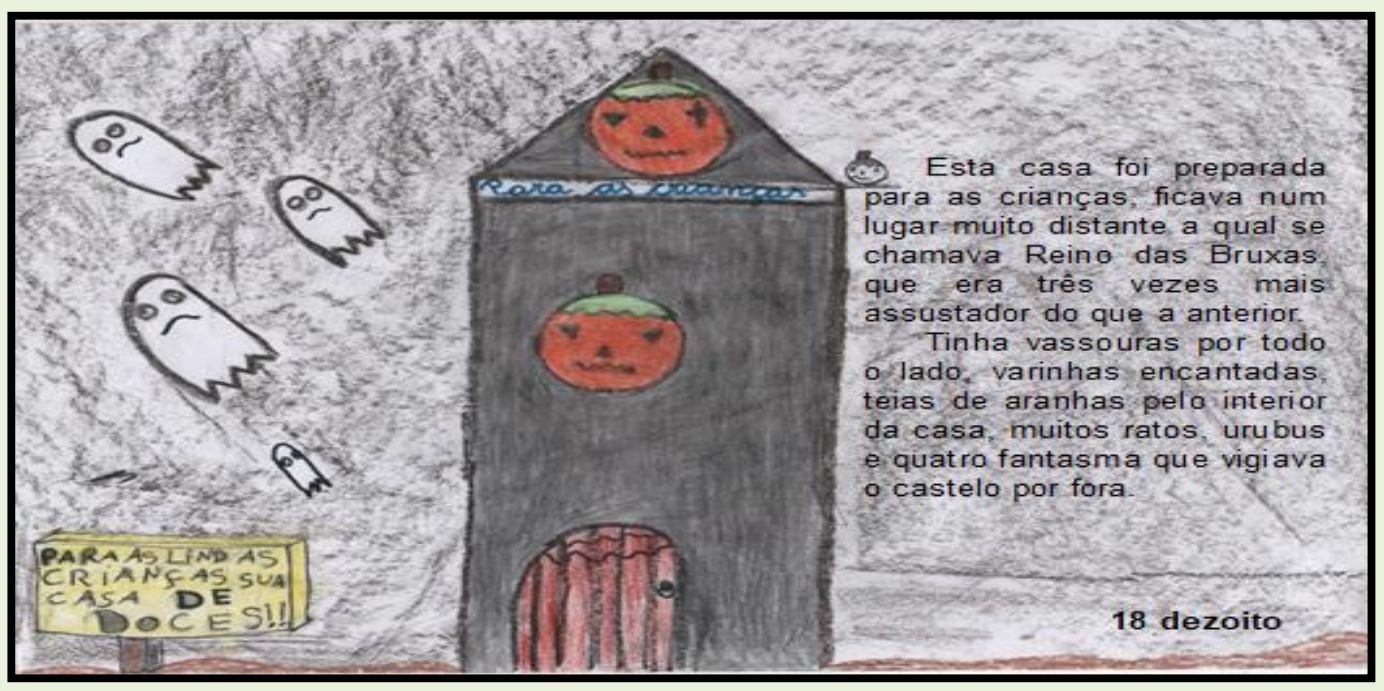

Fonte: Dados da pesquisa (2018).

Os elementos descritos no texto apresentam saberes matemáticos revelados em fragmentos como "três vezes mais", que indica o "triplo" de alguma coisa; outro saber revelado é quando se escreve "tinha", dando ideia de "subtração"; além do desenho da placa em 3D, valorizando o conteúdo de geometria espacial, quando se aponta a altura, largura e espessura (volume). Salientamos que a equipe $3 \mathrm{faz}$ a correlação da leitura visual e oral, oportunizando ao leitor diversas formas de leitura. 
É importante frisar que os saberes geométricos utilizados contribuíram para a construção de elementos essenciais para a representação dos objetos e seres que deram um significado especial à produção textual desse conto.

Com base no que observamos, podemos considerar que se torna importante a inserção de atividades diferenciadas para redimensionar a metodologia tradicional utilizada no ensino básico, com o intuito de explorar o potencial e as diversas formas de raciocínio dos alunos.

Constatamos que a produção escrita de contos nas aulas de Matemática, na perspectiva da resolução de problemas, além de contribuir para o desenvolvimento do raciocínio dos alunos, permitiu desenvolver a criatividade dos alunos a partir de suas experiências de vida e dos conhecimentos matemáticos que the permitiram "novas" compreensões e leituras do mundo e da sua realidade, que são aspectos essenciais à sua formação.

\section{CONSIDERAÇÕES FINAIS}

O estudo realizado proporcionou trabalhar a produção escrita de contos na perspectiva da resolução de problemas de forma mais contextualizada e relacionada com o cotidiano dos alunos, buscando evidenciar os saberes matemáticos.

A criatividade dos alunos resultou em momentos de aprendizagem desafiadores, além da própria produção escrita, por meio da resolução de problemas, que envolveu o raciocínio e a comunicação entre os alunos.

Nesse sentido, o objetivo geral este estudo foi analisar os saberes matemáticos evidenciados nas produções textuais, nas aulas de Matemática, na perspectiva da resolução de problemas.

Durante a investigação, foi possível constatar o desafio enfrentado pelos alunos para desenvolver um raciocínio em várias etapas, visto que esta não é uma prática comum no cotidiano das aulas de Matemática. A intervenção demonstrou que a estratégia de produção de contos por parte dos alunos estimula a livre expressão de ideias bem como a comunicação 
entre os sujeitos que precisam estabelecer o diálogo entre si para que o conto se concretize.

Esses fatos se devem ao ensino tradicional empregado, com o objetivo de que os alunos produzam apenas as respostas esperadas. Outros fatores relevantes a serem ressaltados são a falta de intimidade com a língua materna e a dificuldade de interpretação dos problemas, os quais são fatores que podem restringir e retardar o desenvolvimento do raciocínio dos alunos.

Averiguamos que, ao utilizar a metodologia de resolução de problemas, contribuímos para o desenvolvimento do raciocínio dos alunos, dando-Ihes possibilidade de desenvolver a criatividade a partir de suas experiências de vida e dos conhecimentos matemáticos, que são aspectos essenciais à sua formação. A partir da observação realizada, constatamos que a metodologia tradicional empregada no ensino da Matemática não abrange conhecimentos construídos em suas vivências e observações do mundo ao redor, e que se abordada de forma contextualizada em sala de aula, os saberes matemáticos são ressignificados e construídos em conhecimentos científicos.

Os alunos apontam que a Matemática é uma importante disciplina para a sociedade e o cotidiano; e, ao se apropriarem dos saberes matemáticos básicos, estarão cooperando para a formação de um cidadão crítico, autônomo, ético e social; e os saberes reconstruídos na escola possam também ressignificar as ações cotidianas, convertendo-se numa melhoria na qualidade de vida de todos.

Quanto à interação entres os alunos, estes revelaram, durante o processo, um trabalho colaborativo, uma vez que desenvolveram atitudes de cooperação e colaboração entre os colegas e com os pesquisadores; isso possibilitou com êxito a realização de todas as etapas deste estudo.

Essa atividade possibilitou aos alunos a compreensão de que a Matemática está presente em praticamente tudo, com maior ou menor complexidade, pois o homem tem a necessidade de calcular, contar, 
comparar, localizar, medir, interpretar, e, muitas vezes, faz isso de modo informal.

Em nossas análises, evidenciamos os saberes matemáticos construídos pelos alunos, na escrita e ilustração do conto, dentro os quais destacamos: números e operações (quantidade, números ordinais e naturais); espaço e forma (as formas geométricas, localização, perspectiva); e grandezas e medidas (medida de tempo e capacidades), tornando-se visível a necessidade desse saber construído cotidianamente, para além da escola se incorporar à Matemática escolar, amenizando as características e as distâncias entre as Matemáticas da escola e as Matemáticas e do cotidiano.

$\mathrm{Na}$ perspectiva de estudos futuros, ainda ressoam questionamentos, tais como: Como manter as práticas pedagógicas com o apoio da produção escrita de contos nas aulas de Matemática, numa dimensão da aprendizagem colaborativa? De que modo criar um espaço dialético entre o professor de Matemática e aluno no que diz respeito a temática da produção escrita de contos para compreendermos suas potencialidades e contribuições?

Um mergulho no universo desses sujeitos a partir da utilização da produção escrita de contos nas aulas de Matemática evidencia o entendimento de que é urgente repensar as práticas pedagógicas com este recurso, buscando ajustá-las às necessidades e aos objetivos de cada sujeito, para que incentive a reflexão, a cooperação, a construção de saberes matemáticos e de condutas entre o ensinar e o aprender que sustentem permanentemente o processo educativo dos nossos alunos.

\section{REFERÊNCIAS}

ABAURRE, M. L. Produção de texto: interlocução e gêneros. São Paulo: Moderna, 2007.

BOSI, A. O conto brasileiro contemporâneo. São Paulo: Cultrix, 1975.

BRASIL. Ministério da Educação. Base Nacional Comum Curricular. Brasília: MEC, 2018. 
DINIZ, M. I.; SMOLE, K. S. Ler, escrever e resolver problemas: habilidades básicas para aprender matemática. Porto Alegre: Artmed editora, 2001.

FLICK, U. Uma introdução à pesquisa qualitativa. 2. ed. Porto Alegre: Bookman, 2004.

GOTLIB, N.B. Teoria do conto. São Paulo: Ática, 1990.

LAIZO, A. Tipos de conto. Disponível em:

http://paodecanelaeprosa.com.br/tipos-de-conto-literatura. Acesso em: 30 out. 2019.

NACARATO, A. M.; MENGALI, B. L. da S.; PASSOS, C. L. B. A matemática nos anos iniciais do ensino fundamental: tecendo fios do ensinar e do aprender. Belo Horizonte: Autêntica Editora, 2011.

OLIVEIRA. C.A. O ensino de matemática com tecnologia touchscreen: criar, inventar e manipular na cibercultura. Disponível:

<https://eventos.set.edu.br/index.php/enfope/article/viewFile/8990/3943.> Acesso em: 01 de fevereiro de 2019.

PADOVANI, A. Contar cuentos: desde la práctica hacia la teoría. 1. ed. Buenos Aires: Paidós, 2005.

PANIZZA, M. Ensinar matemática na educação infantil e nas séries iniciais: análises e propostas; tradução Antonio Feltrin. - Porto Alegre: Artmed, 2006.

RÊGO, R. G; PAIVA, J. P. A. A. Tópicos Especiais em Matemática III. In: ASSIS et al. Licenciatura em Matemática a distância, volume 6. Universidade Federal da Paraíba. João Pessoa: Editora Universitária da UFPB, 2009.

SARMENTO, L. L.; TUFANO, D. Português: literatura, gramática, produção de texto: volume único. São Paulo: editora Moderna, 2004.

SMOLE, K. C. S. et al. Era uma vez na matemática: uma conexão com a literatura infantil. $3^{a}$ edição. São Paulo: IME-USP, 1996.

SMOLE, K. C. S.; DINIZ, M. I; CÂNDIDO, P. Matemática de 0 a 6 anos. Porto Alegre: Artmed, 2000.

SMOLE, K. C. S. A Matemática na educação infantil: a teoria das inteligências múltiplas na prática escolar. Porto Alegre: Artmed, 2003.

SOARES, A. Gêneros literários. São Paulo: Ática, 1993.

SOLÉ, I. Estratégias de leitura. Porto alegre: Artes médicas, 1998. 
THIOLLENT, M. Metodologia da pesquisa-ação. São Paulo: Cortez, 2011.

ORTEGA, E.M.V. A construção dos estudantes de pedagogia em relação à matemática e seu ensino no decorrer da formação inicial. 164f. (Tese de Doutorado - Universidade de São Paulo, São Paulo, 2011).

Recebido em: 12 de abril de 2020

Aprovado em: 21 de Junho de 2020

Publicado em: 17 de agosto de 2020 